\title{
Standing Together While We Stay Apart: Your 2021 TMS Membership \\ Tom Battle
}

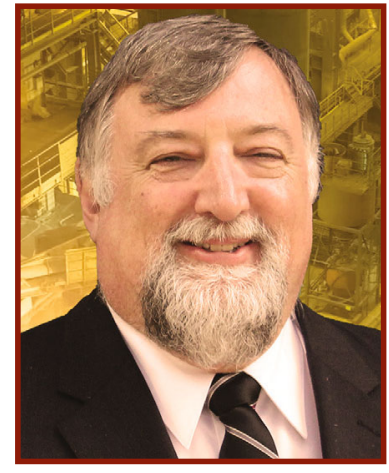

Tom Battle
In the past year, our global professional community - and indeed the entire worldhas been grappling with hard questions. Perhaps central among these, at least professionally speaking, is this: How do we keep science and technology advances moving forward when we're so far apart?

Connecting with colleagues is an essential aspect of our careers as scientists and engineers. We gather with teams of co-workers to solve difficult problems. We work side-by-side in laboratories to test new ideas. We meet at conferences and events to share insights and gather inspiration for our own work. Our careers and our individual projects thrive on this kind of interaction. So how do we keep our momentum going in time of pandemic?

While there are no easy answers to these questions, there is one important thing that all of us can do. We can stand together (figuratively speaking!) as a community. Our TMS community has always been a place that brings together scientists with engineers, industry employees with government lab workers, academic professionals, and students. We have long been the Society that connects individuals working throughout the world to move the minerals, metals, and materials science and engineering fields forward. And we continue to do so today.

One of the easiest ways to show solidarity and to stay connected with your community is to renew your membership in The Minerals, Metals \& Materials Society for the coming year. It doesn't sound like much, but when you renew your membership, your dues help to cover costs associated with the services provided to TMS members, as well as the services we are able to provide to the larger community.

When you renew for 2021, you also help to grow our Society's network of professionals and students, making it easier for individuals to share new ideas, inspire new research directions, and forge new professional relationships. When you renew for 2021, you help to enable all of these connections and interactions to continue happening and you help keep the field moving forward, for both yourself and your colleagues.

For our part, we are working to do all we can to provide additional support to the TMS community during this challenging time. A few examples:

- We have launched a new series of webinars, led by TMS volunteers with a wealth of expertise and experience, on topics of current interest. Log in to www.tms.org/WebinarLibrary to view past webinars for free and to register for upcoming events.

- We've introduced a new Economic Hardship member category for any member who may be dealing with a temporary setback in their career, such as job loss, employer funding cuts, or reduced working hours. You can contact Bryn Simpson, TMS Membership and Volunteerism Program Manager, at bsimpson@tms.org to request this free membership until you are back on your feet.

- We launched a COVID-19 Resource Portal (www .tms.org/COVID-19) that consolidates many resources that members can use as they work from home. This includes the TMS COVID-19 Materials Needs Exchange, which connects organizations and programs on the front lines of the COVID-19 pandemic with TMS members who can render materials or manufacturing assistance, resources, and/or expertise. More than 2,000 users have accessed these resources since April 2020.

- We offered a virtual version of the Metallurgical and Materials Engineering Professional Engineer (PE) Licensing Exam Review Course this year, which helped individuals to continue their preparations for this important test remotely.

- We have also continued to publish high-quality journals that disseminate advances in our field to readers throughout the world. (And it's worth noting just how impactful these journals are - see the article "Impact Factors and Other Key Metrics Released for All Six TMS Journals" in the September issue of $J O M$.) Log in to www.tms.org/Journals to read any of these journals or to learn how to submit your work.

TMS will continue to seek new ways to reach out and connect members with one another, as we all strive to stand together, even as we stay apart. I encourage you to take a few moments of your day to renew your membership, so that you can continue to stand with us.

P.S.: I know it's been a year of changes for many of you, so if you have switched jobs, relocated, or added new technical interests, please be sure to update your member profile information during the renewal process.

You can also update this information at any time through the Member Tools section of members.tms.org.

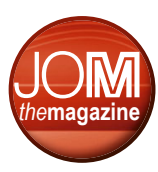

